\title{
EL “IMPERIO INFORMAL” BRITÁNICO EN AMÉRICA LATINA: ¿REALIDAD O FICCIÓN?
}

\author{
Paul Garner \\ University of Leeds \\ El Colegio de México
}

\begin{abstract}
Z ste ensayo presenta un breve repaso de la historiograEfía sobre el Imperio británico en la segunda mitad del siglo xx. Me concentro en tres perspectivas: dos que dominaron la historiografía sobre la expansión imperial británica durante la segunda mitad de siglo xx - el concepto de "imperialismo informal" y el de "el capitalismo de caballeros" - y una tercera, la más reciente - la descripción del historiador británico John Darwin del Imperio británico como un "proyecto imperial”, sumamente diverso, híbrido y nunca terminado; su último libro es precisamente Unfinished Empire: The Global Expansion of Britain (Allen Lane, 2012)-. Los tres textos a los que me voy a referir son el artículo de John Gallagher y Ronald Robinson "Imperialism of Free Trade”, el libro de Peter Cain y Anthony Hopkins British Imperialism (1688-2000), y el de John Darwin The Empire
\end{abstract}

Fecha de recepción: 7 de enero de 2015

Fecha de aceptación: 20 de abril de 2015 
Project: the Rise E Fall of the British World System 18301970. ${ }^{1}$

Aunque estos textos abarcan épocas y cronologías más amplias, voy a centrarme en lo que todos estos autores (y muchos más) reconocen como la época de auge del Imperio británico, las épocas victoriana y eduardiana [los reinados de Victoria (1837-1901) y Edward VII (1901-1910)] en la segunda mitad del siglo xix hasta el fin de la primera guerra mundial, en 1918. Esta época se reconoce ampliamente como una en la que se concentran dos fenómenos claves de la historia mundial - el del desarrollo del Estadonación, y el del auge imperial. En particular me voy a centrar en las relaciones anglolatinoamericanas, y específicamente en las anglomexicanas, para poner en tela de juicio la validez del concepto de "imperio informal".

Sin embargo, primero quisiera comentar algo sobre el vínculo profundo que existe entre el estudio de las relaciones diplomáticas y comerciales británicas con América Latina y la historiografía británica sobre esta región. Hay varias explicaciones del afán de los historiadores pioneros británicos por centrarse en estos campos. En primer lugar, el estatus marginal de las colonias británicas "formales" en la región, aun en la época de auge del Imperio británico durante la segunda mitad del siglo xIX, que contrastaba fuerte y simultáneamente con la importancia de sus conexiones "informales" (comerciales y financieras). Como consecuencia, las colonias “formales” (Honduras Británica, Guyana Británica y las Islas Malvinas) han sido doblemente margi-

${ }^{1}$ Gallagher y Robinson, “The Imperialism”; Cain y Hopkins, British Imperialism; DARWIN, The Empire. 
nales, tanto para el Imperio británico como para la historiografía británica sobre América Latina. En segundo lugar, existían dificultades prácticas y logísticas para acceder a las fuentes primarias, dada la escasez de programas académicos sobre América Latina en el Reino Unido, y había pocos fondos disponibles para la investigación de temas latinoamericanos antes de la década de $1970 .^{2}$ Como consecuencia, los primeros estudios británicos se centraron en el papel de Gran Bretaña en el proceso de independencia en América Latina y en el desarrollo de vínculos comerciales y diplomáticos con las nuevas repúblicas latinoamericanas a lo largo del siglo XIx. ${ }^{3}$

Sin embargo, si la dependencia exclusiva de la historiografía británica de fuentes británicas era inevitable, resultó al mismo tiempo desafortunada, puesto que esas fuentes, por un lado, enfatizaban la "neutralidad benigna” y la "distancia” tanto del Foreign Office como de los representantes del Gobierno de Su Majestad en el servicio diplomático en las repúblicas latinoamericanas. Por otro lado esas fuentes dieron pocos indicios de una influencia deliberada, o aún menos exitosa, por parte de los funcionarios del Foreign Office o de los agentes consulares británicos sobre la dirección de la política económica de los nuevos gobiernos latinoamericanos. La ausencia de "influencias" - o, como lo

${ }^{2}$ El Informe Parry, que investigaba el estatus de los estudios latinoamericanos en Gran Bretaña en 1967, condenó los niveles generales de ignorancia y prejuicio que caracterizaban el conocimiento de los británicos sobre la región. El informe abrió paso a la fundación en los años setenta de cinco Centres of Latin American Studies en las Universidades de Londres, Oxford, Cambridge, Liverpool y Glasgow; MarTin, "Britain's Cultural”. ${ }^{3}$ Humphreys, British. 
describen Cain y Hopkins, del poder "suave" (soft) o "relacional" - fue exacerbada por los desacuerdos frecuentes y las divisiones institucionales entre las agencias responsables de la política exterior británica hacia América Latina. Como indica Rory Miller, antes de 1920 el Foreign Office y el servicio diplomático eran instituciones separadas, con poco contacto entre una y otra. ${ }^{4}$

Además, los que hemos trabajado los archivos diplomáticos británicos sabemos muy bien que las fuentes diplomáticas son muy citadas. Normalmente están escritas con buena pluma por individuos con un alto nivel de educación, pero también con un alto nivel de prejuicio racial y de clase. Por ejemplo, el funcionario encargado de la Legación británica en México en 1910 describió a Francisco I. Madero como un "espiritista y vegetariano" que "definitivamente no era apto, ni era el tipo de hombre que pudiera gobernar México". Al mismo tiempo demostró su ignorancia y falta de sensibilidad al informar al Foreign Office que en 1910 "no había ni la posibilidad más remota de que hubiera una revolución en México". ${ }^{5}$ Por otro lado, la historia construida sólo con base en fuentes diplomáticas británicas inevitablemente subestimaba la importancia del contexto económico, social y político local en el que operaban los intereses británicos. En resumen, la alta dependencia de fuentes británico céntricas, sobre todo de las fuentes diplomáticas, distorsionaba tanto la historiografía del Imperio británico como aquella sobre relaciones británicas con

\footnotetext{
${ }^{4}$ Miller, Britain, pp. 48-49.

5 T. B. Hohler a Sir Edward Grey, National Archives, Kew, London Foreign Office 371/1149/1574.
} 
América Latina y, por ende, hizo difícil una comprensión más amplia y más profunda del carácter de los contactos “imperiales” británicos en la región.

\section{EL RETO DE LA TEORÍA DE LA DEPENDENCIA Y DEL “IMPERIALISMO INFORMAL”}

No obstante, después de los años sesenta, la historiografía nacionalista, estructuralista y dependentista representó un fuerte reto a la interpretación benigna del papel de los británicos, y rápidamente llegó a predominar en la academia a ambos lados del Atlántico. La tesis nos es familiar. Se describía una región esclavizada en el siglo xIx por un proceso de explotación neocolonial y un desarrollo distorsionado que tuvo como consecuencia una grave pérdida de soberanía, económica y política. Dado que Inglaterra, la potencia marítima predominante en el mundo atlántico del siglo XIX, era defensora del libre comercio, los aranceles bajos y "la moneda fuerte" en un entorno económico mundial claramente asimétrico y "divergente", su complicidad en la perpetuación del subdesarrollo de América Latina fue siempre de capital importancia para esa tesis. ${ }^{6}$

Al mismo tiempo que la teoría de la dependencia montaba un asalto a la academia mundial, la historiografía del Imperio británico experimentaba un grado parecido de turbulencia. El análisis de Gallagher y Robinson en su artículo "Imperialism of Free Trade" puso en tela de juicio la historiografía del Imperio británico. Estos autores identificaron dos fases en la expansión imperial de Gran Bretaña en el siglo xix: la

${ }^{6}$ Cardoso y Faletto, Dependency; Pomeranz, The Great Divergence. 
primera, entre 1815 y 1870; la segunda, entre 1870 y el inicio de la primera guerra mundial (1914). En la primera, mientras que el padrón “normal” o "clásico” de la expansión imperial británica había sido la anexión militar de territorios de ultramar en búsqueda de nuevos mercados y fuentes de materias primas para alimentar a la industria británica, arguyeron que los responsables de la política imperial recurrían al mismo tiempo a tácticas de influencia, presión e intimidación menos directas, más flexibles, más “informales”. El imperialismo “informal”, según el argumento, estaba imbuido de realpolitik y fue siempre pragmático y preferible al imperialismo "formal” (territorial, militar, burocrático), no solo por ser menos costoso, sino por ser igualmente efectivo o eficaz al asegurar la "preeminencia” (paramountancy) británica por medio de alianzas con élites colaboradoras en "la periferia semi-colonial”.

Después de 1870, según Gallagher y Robinson, cuando el poder industrial británico empezó a sufrir los vientos fríos de la competencia internacional, y como otras naciones industrializadas buscaban extender sus propias esferas de influencia imperial, la élite política (Westminster) y la burocrática (Whitehall) vieron necesaria una intervención imperial más “clásica” y vigorosa, basada en la fuerza militar, para proteger los intereses imperiales británicos. Esto explica, según dichos autores, la entusiasta participación británica en lo que la historiografía llama la "Pelea por África” (Scramble for Africa) después de 1885, consecuencia de la competencia entre los poderes imperiales europeos (Francia, Alemania, Italia y Bélgica). ${ }^{7}$

7 Louis, Imperialism; Brown (ed.), Informal Empire. 
Es importante subrayar que las raíces ideológicas de la teoría de la dependencia y la del imperio informal fueron diferentes. La primera se inspiró en el marxismo y el estructuralismo, mientras la segunda se concebía como un desafío al determinismo marxista. Las dos coincidieron, sin embargo, en identificar la clave del desarrollo (o, mejor dicho, el subdesarrollo) de América Latina en sus relaciones con el exterior, y las dos argumentaban que el Imperio británico fue un sistema global que tuvo un impacto fuerte (y según el dependentismo, claramente negativo) sobre el desarrollo de la región.

Sin embargo, las ortodoxias de la dependencia y del imperialismo informal han sido repetidamente cuestionadas. En mi inicio $-y$, quizá previsible - hubo una respuesta defensiva de los historiadores británicos empíricos de la economía, como Cristopher Platt que, de manera muy británica, detectaba en 1980 un "fuerte olor a odium scholasticum" en este debate acalorado. ${ }^{8}$ Platt propuso varias críticas a estos modelos. En primer lugar, hizo notar que el gobierno británico se rehusaba de manera consistente a intervenir para proteger los intereses de los empresarios y tenedores de bonos británicos. Como resultado, no se vieron casos significativos de "diplomacia de las cañoneras" (gunboat diplomacy) británicas en América Latina. En segundo lugar, argumentaba que los niveles de comercio entre Gran Bretaña y América Latina durante la primera mitad del siglo xIx fueron, para Gran Bretaña por lo menos, insignificantes.

En tercer lugar, aun cuando América Latina empezó a integrarse a la economía internacional en la segunda mitad del siglo xix por medio de un número restringido de

${ }^{8}$ Platt, “Dependency”, pp. 113-149. 
exportaciones, la especialización en las exportaciones fue una consecuencia natural de la ventaja comparativa, y no un resultado de la coerción imperial. En cuarto lugar, en vez de insistir en que las prácticas empresariales en América Latina deberían seguir el modelo anglosajón, los empresarios británicos se adaptaron a las circunstancias y prácticas locales. ${ }^{9}$ Por último, Platt argüía que los avances materiales de las economías latinoamericanas en el último cuarto del siglo XIX no condenaron a los estados latinoamericanos en embrión al subdesarrollo estructural, sino que ayudaron al desmantelamiento (o "difusión”) de los bien conocidos obstáculos al desarrollo: la ausencia de un mercado nacional integrado, aranceles internos prohibitivos, infraestructura de transporte costosa e inadecuada, un aparato estatal débil, falta de regulación del comercio y escasez crónica en la inversión. ${ }^{10}$

Más recientemente, los historiadores de la corriente empírica de la "nueva” historia económica han intentado dar el golpe de gracia al análisis basado en la teoría de la dependencia, desestimándolo como imposible de probar, acientífico y contrario a los hechos. ${ }^{11}$ En vísperas del siglo xxI, según Allen Wells, la teoría de la dependencia representaba un "caballo muerto" que ya no merecía ser azotado. ${ }^{12}$ Sin embargo, se hizo un intento por revivir "el caballo azotado” en el contexto de los estudios del Imperio británico en

${ }_{9}$ Un ejemplo de la adaptación como fuente del éxito empresarial de los británicos en el México decimonónico se encuentra en Garner, British Lions. 10 Platt, Finance; Platt, Latin America; Platt (ed.), Business Imperialism.

${ }^{11}$ Haber, "Economic Growth".

${ }^{12}$ Creo que el equivalente a la metáfora en inglés "to flog a dead horse" es "machacar en hierro frío" o "predicar en el desierto". 
el libro de Cain y Hopkins antes citado, British Imperialism, publicado por primera vez en 1993 y de nuevo en 2001. Sin duda este libro ha tenido gran impacto en la historiografía del Imperio británico. ${ }^{13} \mathrm{El}$ análisis de Cain y Hopkins se basa en tres elementos centrales: las estructuras económicas fundamentales de la sociedad británica - financiera, comercial e industrial - que sostenían el poder imperial; una élite social y política que reunía elementos "tradicionales" (aristocráticos, basados en la tenencia de la tierra) y "modernos" (nouveauxriches, orientados hacia el mercado, con su base en la City of London) que buscaban una política coherente de expansión comercial e imperial; y finalmente, en lo que constituye el elemento más importante de la hipótesis, se ponía énfasis en las características de la relación entre estos elementos claves y las estructuras de control político y dominio comercial que gobernaban el Imperio británico. Aquí se reconoce la deuda de Cain y Hopkins con Gallagher y Robinson, ya que estas estructuras se describían como "formales" - en los casos que desembocaron en una ocupación territorial y en la implementación de marcos de gobierno constitucionale "informales", donde el aparato completo de asentamiento colonial no se consideraba ni apropiado ni necesario.

$\mathrm{El}$ argumento central de British Imperialism era el siguiente: el rápido crecimiento del sector servicios en la economía británica constituyó "la clave para entender la característica peculiar o sui generis de la expansión del imperialismo británico" ("the key to a better understanding of the peculiar nature of British overseas expansion and imperialism"). Para estos autores, los elementos centrales del "capitalismo de

${ }^{13}$ Dumetr (ed.), Gentlemanly. 
servicios" (service-sector capitalism) - la banca, los seguros, las comunicaciones, el transporte, y los servicios públicos y personales - no solo fueron los sectores más dinámicos de la economía, sino la fuerza motriz del imperialismo. Éste fue producto de una alianza, basada en afinidades culturales y de clase, entre la élite política - lo que en Gran Bretaña se describe como la élite "Westminster" - , la de funcionarios - los Mandarins of Whitehall - y la financiera - The City of London-, que funcionó según un código de comportamiento “de caballeros", y persiguió una política imperial coherente y consensada. La prioridad fue mantener la libra esterlina como el medio principal del comercio internacional, mediante la adhesión al estándar de oro; la segunda, garantizar una política de finanzas públicas sólidas y controladas: en síntesis, una política imperial de "comercio libre, impuestos bajos, y moneda sólida" (free trade, low taxation, and sound money).

British Imperialism tuvo un impacto profundo, ya que planteó un reto a las tesis antes aceptadas y no cuestionadas sobre el carácter esencial del Imperio británico y sus orígenes, así como acerca de la periodización de su historia. Primero, problematizó la tesis de que fueron los intereses industriales y del sector manufacturero los que habían impulsado la expansión imperial; segundo, modificó una cronología imperial que ahora se extendía desde finales del siglo XVII hasta las postrimerías del xx, que rebasaba el supuesto desmoronamiento de la industria británica a fines del siglo XIX.

El tercer texto en mi trilogía de perspectivas historiográficas sobre el Imperio es el de John Darwin en su The Empire Project: The Rise and Fall of the British World System 
1830-1970. Darwin reconoce ampliamente su deuda tanto con Gallagher y Robinson como con Cain y Hopkins. A Gallagher y Robinson les reconoce la importancia de la visión del alcance global del Imperio británico, así como su análisis sistemático y, al mismo tiempo, su énfasis en la estructura flexible y pragmática del Imperio, que evita verlo como una sencilla acumulación de colonias. Reconoce el mérito de los segundos en identificar uno de los cuatro componentes clave del Imperio, el único que no se basaba en la ocupación territorial: la presencia comercial y financiera de la City. Los otros tres componentes clave del sistema imperial eran, según Darwin, territoriales; primero, las propias Islas Británicas, con su poder militar, diplomático, cultural, financiero, comercial y de manufactura; segundo, la India, la famosa "joya de la corona imperial", que fue tan importante para el sistema que hasta constituía, según Darwin, un subimperio que llegó a tener sus propios satélites en la región del sur asiático; tercero, los White Dominions (Canadá, Australia, Nueva Zelanda y Sudáfrica), sociedades de colonizadores con distintos sistemas de autogobierno. Además de subrayar la importancia fundamental de la India y los Dominios Blancos en el sistema imperial británico, la mayor contribución de Darwin es identificar la paradoja central en el corazón del sistema: a pesar de su extraordinaria diversidad - desde colonias bajo gobierno directo (como la India), hasta colonias que se autogobernaban (Canadá, Australia, Nueva Zelanda, Sudáfrica); desde protectorados (como Sudán); fortalezas navales (Gibraltar, Malta) o puertos de tratado (treaty-ports, como Shanghai), hasta territorios ocupados (Egipto y Chipre) - se puede identificar un sistema coherente, aunque en flujo constante, que dependía 
no sólo de la interacción entre sus diferentes partes, sino de la interacción con fuerzas políticas, económicas y culturales globales que estaban fuera y más allá de su control. En síntesis, este sistema fue interdependiente, y tuvo objetivos militares, estratégicos, comerciales y culturales claramente identificables, pero, al mismo tiempo, fue caótico, inacabado, nunca autosuficiente o hermético y, sin lugar a duda, nunca omnipotente.

\section{IMPERIALISMO INFORMAL EN AMÉRICA LATINA:}

¿FICCIÓN O REALIDAD?

Ahora al grano: cada una de estas tres perspectivas ha tenido un impacto profundo sobre los estudios del Imperio británico, pero no han carecido de críticas. De los tres, el texto más polémico ha sido el de Cain y Hopkins. Sus críticos han cuestionado varios aspectos de su hipótesis: por ejemplo, la polarización entre los intereses de las élites aristocráticas, políticas y financieras, supuestamente dominantes sobre la política imperial, y los del sector industrial, según esto más débil. Se ha cuestionado también la homogeneidad de esta "élite de caballeros”, ya que pertenecían a una gama extensa de instituciones y a distintas organizaciones [la Cancillería (Treasury), el Banco de Inglaterra, el Foreign Office, el servicio diplomático, el Almirantazgo, la Secretaría de Guerra].

También se ha criticado la renuencia a considerar los contextos más amplios y sumamente diversos a lo largo y ancho del imperio: el ámbito local en el cual se ejercían los intereses imperiales, en donde los intereses endógenos siempre intentaron, y muchas veces lograron, influir, modificar y resistir la autoridad colonial. Esto subraya quizás el principal 
problema de la tesis de Cain y Hopkins: es, en el fondo, una visión muy anglocéntrica. También es una crítica que se podría hacer, quizá en menor grado, tanto a Gallagher y Robinson como a Darwin, sobre todo cuando se examina el caso específico de las relaciones entre los intereses imperiales británicos y los estados independientes de América Latina en el siglo XIX.

En su defensa, hay que decir que Cain y Hopkins prestan más atención al contacto británico con América Latina en el siglo xix que Gallagher y Robinson o el mismo Darwin. Examinan los casos específicos de Argentina, Brasil y Chile en el siglo xIx, países en los que, hacia 1914, se concentraba $85 \%$ del comercio británico con América Latina, y $69 \%$ de las inversiones británicas en la región. Sin embargo, aun cuando los autores reconocen la contribución positiva de la inversión comercial extranjera en el desarrollo de la infraestructura económica y la construcción de los estados nación de la América Latina decimonónica, llegaron a la conclusión de que el control británico del comercio y las finanzas en esos países era tal que "infringía” su soberanía nacional. En consecuencia, afirman, durante la segunda mitad del siglo, Inglaterra ejerció en esos países un "dominio honorario" - una versión un poco diluida, según parece, del "imperialismo informal".

Cain y Hopkins se rehusaron a "agrupar" las relaciones entre la Gran Bretaña y América Latina en un solo paradigma estructural. Por el contrario, hicieron énfasis en el hecho de que, como siempre lo han sabido los historiadores latinoamericanos, en el siglo xix América Latina no constituía - ni ha constituido nunca - un mercado indiferenciado para la inversión y el comercio británicos. Es, curiosamente, un 
análisis más sensato que los de Gallagher y Robinson o el del mismo Darwin, quienes tendían a asumir que las relaciones imperiales británicas con América Latina, si no eran homogéneas, tenían sin embargo el mismo carácter.

De modo más trascendente, en el contexto de este volumen de ensayos, México no forma parte del paradigma imperial de Cain y Hopkins. Aunque esa ausencia nunca se explica o justifica, es una omisión significativa, ya que los indicios sugieren que México no se ajusta a dicho paradigma. ${ }^{14}$ En realidad, se podría argumentar que no corresponde en absoluto. Según Cain y Hopkins, para "calificar" para la condición de sujeción al imperialismo británico, las economías receptoras tenían que ser "marcadamente dependientes del comercio y el crédito británicos" y estar "obligadas a adaptarse al liberalismo político y económico británico", ${ }^{15}$ lo cual, no fue el caso de México en ningún momento del siglo XIX, ni siquiera durante el auge del poder imperial británico a partir de 1850. Ello se debió a dos razones fundamentales: la primera fue que México estuvo aislado de las fuentes de capital y crédito de los mercados financieros europeos desde el decenio de 1830 hasta finales de 1880 (con la excepción del caso muy especial de los petit-bleus o maximilianitos de 1864 y 1865, estudiados por Steven Topik); ${ }^{16}$ la segunda, el desarrollo, a partir de 1867, de lazos económicos cada vez más estrechos con su depredador vecino del norte, Estados Unidos. ${ }^{17}$

\footnotetext{
14 Significativa sobre todo debido a la importancia de la Nueva España como la joya de la corona imperial española.

15 Cain y Hopkins, “Afterword”.

16 Topik, "When Mexico".

17 Riguzzi, “México, Estados Unidos y Gran Bretaña”, pp. 365-437.
} 
Más allá del breve (y hay que insistir, muy breve) apoyo de Gran Bretaña a la abortada "incursión imperial en contra de la soberanía” de México por parte de Francia en 1862, existen muy pocos indicios que sugieran que Gran Bretaña hubiera podido valerse con exito de lo que Cain y Hopkins definen como su poder "estructural" (financiero o militar y naval) o de su menos formal poder "relacional" (presiones, coerción, intimidación) para obligar a la élite política mexicana a ajustarse a los intereses de la City of London, y mucho menos a "copiar aspectos de los procedimientos constitucionales británicos" ni, sin duda alguna, a "adoptar los valores culturales caballerosos de la élite británica”. ${ }^{18}$

A pesar de la demostrable anglofilia de varios miembros de la élite política del México decimonónico, a ésta le impresionaba más, por lo general, la cultura francesa que la británica. Lo más significativo es que esta élite se interesaba aún más en discutir la naturaleza de la propia cultura e identidad nacional, así como a debatir la senda que debía seguir el desarrollo del Estado y de la nación. En su afán por seguir este camino, en el último cuarto del siglo xix esta élite adoptó una serie de medidas con el propósito de (para citar a Cain y Hopkins) "dar una base sólida a la política monetaria y fiscal” y así poder reunir fondos en los mercados financieros europeos para sus proyectos de infraestructura. Esto, sin duda alguna, no se debió únicamente a que la City of London o la Foreign Office británica hubiesen decidido que debía ser así. En su búsqueda del elusivo objetivo del desarrollo nacional, a lo largo de la segunda mitad del siglo xix, la élite política de México (y esto incluye

18 Cain y Hopkins, "Afterword". 
al gobierno de Maximiliano) buscó aprovechar las nuevas oportunidades comerciales y los avances tecnológicos de la primera globalización. El empeño para llevar a cabo los cambios estructurales que requería la economía mexicana durante el periodo de estudio fue tanto nacional/doméstico/interno como externo/internacional/global.

\section{CONCLUSIÓN}

Necesitamos (y debemos) seguir preguntando cuál fue la relación entre las repúblicas independientes de América Latina y el sistema imperial británico en el siglo xIx. El análisis de Gallagher y Robinson, como el de Darwin, se enfocan en la continuidad y coherencia del proyecto imperial - esencialmente la protección y promoción de la supremacía comercial - pero, al mismo tiempo, en su flexibilidad de estrategia y política. Los dos citan los casos de Argentina y Brasil, pero por lo general no prestan gran atención a América Latina y tienden a agrupar las relaciones anglolatinoamericanas bajo un paradigma homogéneo. En contraste, Cain y Hopkins reconocen que las relaciones anglolatinoamericanas no fueron homogéneas, pero solamente exploran los casos de Argentina, Brasil y Chile, donde, según ellos, Gran Bretaña ejerció claramente un "Domino honorario" sobre estos países a finales del siglo XIX.

Persiste sin embargo una pregunta clave: si los conceptos de "imperio informal" o "domino honorario" son válidos, ¿cuán profundos tienen que ser los vínculos, y los niveles de coerción o intimidación para calificarse con estos términos? Dos comentarios finales: primero, en ninguno de estos tres textos se considera seriamente la eficacia (en inglés, agency) 
de las élites políticas en sus contactos con el proyecto imperial, o que los proyectos de construcción de estado y nación en las repúblicas latinoamericanas hayan tenido un impacto sobre el carácter de las relaciones. Su papel se ve siempre como subordinado. Segundo, en ninguno de estos análisis se considera el caso de México, lo cual constituye un vacío historiográfico no solo inexplicable e injustificado, sino a un tiempo serio y trascendental, que, por lo tanto, tiene que llenarse, explicarse y corregirse.

\section{SIGLAS Y REFERENCIAS}

Brown, Matthew (ed.)

Informal Empire in Latin America: Culture, Commerce, and Capital, Oxford, Blackwell, Society for Latin American Studies, 2008.

Bulmer-Thomas, Victor (ed.)

Britain and Latin America: A Changing Relationship, Londres, Royal Institute of International Affairs, 1989.

Cain, Peter y Anthony Hopkins

British Imperialism: 1688-2000, Harlow, Inglaterra, Longman, 1993.

"Afterword: The Theory and Practice of British Imperialism", en Dumetт (coord.), 1999, pp. 196-220.

Cardoso, Fernando Henrique y Enzo Faletto

Dependency and Development in Latin America, Berkeley, University of California Press, 1979.

DARWIN, John

The Empire Project: The Rise and Fall of a British World System, Cambridge, Cambridge University Press, 2009. 
Dumetт, Raymond (ed.)

Gentlemanly Capitalism and British Imperialism: The New Debate on Empire, Harlow, Inglaterra, Longman, 1999.

Gallagher, John y Robert Robinson

“The Imperialism of Free Trade", en Economic History Review, 6:1 (1953).

Garner, Paul

British Lions and Mexican Eagles: Business, Politics, and Empire in the Career of Weetman Pearson in Mexico, 1889-1919, Stanford, Stanford University Press, 2011.

Haber, Steven

"Economic Growth and Latin American Economic Historiography", en Steven Haber (coord.), How Latin America Fell Behind: Essays on the Economic Histories of Brazil and Mexico, 1800-1914, Stanford, Stanford, University Press, 1997, pp. 1-33.

Humphreys, Robin

British Consular Reports on the Trade and Politics of Latin America 1824-1826, Londres, Offices of the Royal Historical Society, 1940.

Louis, William Roger (ed.)

Imperialism: The Robinson and Gallagher Controversy, Nueva York, New Viewpoints, 1976.

Martin, Gerald

"Britain's Cultural Relations with Latin America", en BuLMER-Thomas (ed.), 1989, pp. 27-51.

Miller, Rory

Britain and Latin America in the Nineteenth and Twentieth Centuries, Harlow, Inglaterra, Longman, 1993. 
Platt, Christopher

Finance, Trade and Politics in British Foreign Policy, 18151914, Oxford, Oxford University Press, 1968.

Latin America and British Trade 1806-1914, Nueva York, Harper \& Row, 1973.

"Dependency in Nineteenth-Century Latin America: An Historian Objects", en Latin American Research Review, xv: 1, 1980, pp. 113-149.

Platt, Christopher (ed.)

Business Imperialism 1840-1930: An Enquiry Based upon British Experience in Latin America, Oxford, Oxford University Press, 1977.

Pomeranz, Kenneth

The Great Divergence: China, Europe, and the Making of the Modern World Economy, Princeton, Princeton University Press, 2000.

Riguzzi, Paolo

"México, Estados Unidos y Gran Bretaña, 1867-1910: una difícil relación triangular", en Historia Mexicana, XLI:3 (163) (ene.-mar. 1992), pp. 365-437.

Topik, Steven

"When Mexico Had the Blues: A Transatlantic Tale of Bonds, Bankers, and Nationalists, 1862-1910”, en American Historical Review, 105 (2000), pp. 714-738. 
